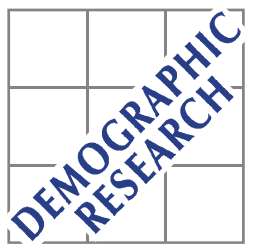

Demographic Research a free, expedited, online journal

of peer-reviewed research and commentary in the population sciences published by the Max Planck Institute for Demographic Research

Konrad-Zuse Str. 1, D-18057 Rostock · GERMANY

www.demographic-research.org

DEMOGRAPHIC RESEARCH

VOLUME 16, ARTICLE 15, PAGES 469-492

PUBLISHED 01 JUNE 2007

http://www.demographic-research.org/Volumes/Vol16/15/

DOI: 10.4054/DemRes.2007.16.15

Research Article

Does cancer affect the divorce rate?

Astri Syse
Øystein Kravdal

(C) 2007 Syse \& Kravdal

This open-access work is published under the terms of the Creative Commons Attribution NonCommercial License 2.0 Germany, which permits use, reproduction \& distribution in any medium for non-commercial purposes, provided the original author(s) and source are given credit.

See http:// creativecommons.org/licenses/by-nc/2.0/de/ 


\section{Table of Contents}

$\begin{array}{lll}1 & \text { Introduction } & 470\end{array}$

$2 \quad$ Possible effects of cancer on divorce rates 471

2.1 General determinants of divorce 471

$\begin{array}{lll}2.2 & \text { Fertility } & 472\end{array}$

$2.3 \quad$ Intimacy and sexuality 473

$2.4 \quad$ Income and education 473

$2.5 \quad$ Family orientation and obligations 474

$2.6 \quad$ Other potential mediators 474

2.7 Interaction effects 475

$2.8 \quad$ Potential confounders 476

3 Data and method $\quad 477$

$\begin{array}{lll}3.1 & \text { Data } & 477\end{array}$

$\begin{array}{lll}3.2 & \text { Statistical approach } & 477\end{array}$

3.3 Detailed model specifications 478

$4 \quad$ Results $\quad 479$

4.1 The size of the material 479

4.2 Overall effects 480

$4.3 \quad$ Site-specific effects 482

4.4 The importance of cancer stage and prognosis 484

4.5 Cancer before or after marriage 485

4.6 Age interactions 485

4.7 Fertility and education as mediating factors? 486

$5 \quad$ Discussion and conclusion $\quad 486$

6 Acknowledgements $\quad 488$

References $\quad 489$ 


\title{
Does cancer affect the divorce rate?
}

\author{
Astri Syse ${ }^{1}$ \\ $\emptyset_{\text {ystein Kravdal }}^{2}$
}

\begin{abstract}
Discrete-time hazard regression models were employed to register and census data on 1.4 million Norwegian married couples from 1974-2001 to explore the probability of divorce following cancer illness. Divorce rates for around 215000 persons diagnosed with cancer were compared to divorce rates for persons for whom all the other observed variables were the same. No overall harmful influence of a cancer diagnosis was observed. Most cancer forms resulted in small, immediate declines in divorce rates the first years following diagnosis. Exceptions were significant increases in the divorce rates for persons diagnosed with cervical and testicular cancer.
\end{abstract}

${ }^{1}$ Cancer Registry of Norway, Montebello, N-0310 Oslo, Norway; Fax: +47 22451370.

E-mail: astri.syse@medisin.uio.no

${ }^{2}$ Department of Economics, Section for Demography, University of Oslo, Norway. Centre for Advanced

Study, Norwegian Academy of Science and Letters, Norway. E-mail: okravdal@econ.uio.no 


\section{Introduction}

Cancer strikes the population in developed countries heavily. In Norway, between onethird and one-half of the population will ever be diagnosed with a malignant disease, and more than one-fifth of the deaths are reckoned as due to such diseases. Although the cancer incidence generally rises with age, thereby causing the number of cancer patients to increase sharply in ageing populations, many also get the disease as children, adolescents, or young adults.

The possibility of surviving and not having severe symptoms is, of course, the key issue for a cancer patient and his or her family, and society's efforts are to a large extent directed towards providing potentially curative treatment or palliative care. However, the quality of life in a somewhat broader perspective among those who are about to deal with the disease, or those who apparently have survived and regained their health, is also a legitimate concern. Are people with a cancer diagnosis for example more likely to have economic problems in the long run than others? Will they be able to reach their educational goals? How are their chances of finding a spouse or partner, becoming parents, or having more children? Will their marital relationships take a turn for the better or worse? Knowledge of common outcomes may help individual patients and families plan their lives, and serve as an important basis for any societal attempts to assist.

Our analysis explores how cancer affects the probability of divorce among Norwegian couples. In addition to being an important question for those concerned with cancer patients' welfare, it would be interesting from a more general family-behaviour perspective to learn how a stressful event and process such as a malignant disease affects marital relationships.

Several investigations suggest that people with poor health are less likely than others to enter marital unions and have satisfactory and long-lasting relationships (e.g. Blekesaune, Øverbye, and Romøren 2003, Joung et al. 1998, Lillard and Panis 1996, Waldron, Hughes, and Brooks 1996). Cancer does not, however, necessarily have the same impact on family relations as other common illnesses. The development of a malignant disease is often particularly hard to predict, the lethality is very high in many cases, and such a disease may not be associated with the same stigma as those that are more obviously a result of people's life-style and lack of socioeconomic resources (Goldberg and Cullen 1985). Few studies have focused on the effect of cancer in particular, and they have often been based on small samples and been limited to the first years after diagnosis. Most of these small studies have shown no change, or a decrease, in the divorce probability after cancer (Joly et al. 2002, Dorval et al. 1999, Joly et al. 1996, Rieker et al. 1989), but there have been indications of increased marital instability after brain cancer (Glantz et al. 2001, Byrne et al. 1989). 
In this study, we estimate how divorce rates are influenced by various common cancer forms among women and men, using data for the entire Norwegian population extracted from the Cancer Registry, the Central Population Register and recent censuses. No earlier investigation has employed such a large data material. In addition to comparing effects across cancer sites, we explore how they vary with duration since diagnosis, stage of the disease at the time of diagnosis, and age. This has not been done in other studies.

\section{Possible effects of cancer on divorce rates}

\subsection{General determinants of divorce}

There are several reasons why cancer may affect the divorce rate. To facilitate a discussion, we will first review the general factors behind disruptions, under inspiration from an economic-demographic theoretical framework (Becker 1991, Becker, Landes, and Michael 1977). A plausible assumption is that there is a balance at the time of marriage, in the sense that both partners perceive they are better off in this union than alone, and that they believe they are unlikely to find a partner that makes life so much better that it is worth continuing to search. What may disturb this balance and hence lead to divorce?

Seen from a woman's perspective, one possibility is that she somehow becomes more attractive to males, for instance because of a large inheritance. She may then want to leave her spouse in order to search for a 'better' partner with whom she would be happier, and by whom she is now more likely to be accepted. Another possibility is that a better partner who would be pleased to pair up with her may simply show up. When judging whether she will be more satisfied with a new partner, there are of course many gains and losses she may take into account, including those for possible children and perhaps even the possibly reduced well-being of the spouse who is left.

As part of this process, the spouse may 'put up a fight' to keep her, and the marriage may be saved if he has enough to offer her without himself becoming so uncomfortable that he would be more satisfied alone. However, even if she feels that she, after all, would be more happy in another relationship, there would be an additional requirement for a split-up: her increase in happiness would have to be sufficiently large compared to any remorse she may feel in relation to her husband and possible children, as well as any distress she may feel about breaking norms about appropriate family behaviour. In addition, her presumed increase in happiness must be compared to the practical one-time costs associated with the disruption itself (e.g. costs of moving and resettling, and perhaps legal costs to lawyers). 
Alternatively, she may want to live alone or perceive that life will be better with another partner because the qualities of the spouse have deteriorated. He may, for instance, have experienced a loss of economic resources, developed a stronger interest in non-familial activities, or become more aggressive. The relationship may also have become poorer for reasons that cannot be attributed to any particular partner. The chance that it becomes so poor that she thinks it would be best to break out will be particularly large if the quality of the relationship was relatively low already at the time of marriage, although above the level both partners would require for marrying.

Duration is obviously a relevant issue in these considerations. In particular, since there are certain costs involved, a divorce would hardly be worthwhile unless the advantages of having another partner or being single last for a substantial period of time.

For reasons further discussed below, a sudden and potentially fatal illness such as cancer may operate through several of these factors: the quality of the union may be influenced, for better or worse, by whether one partner has had cancer before marriage; the quality may be affected by a later malignancy; the well-being of the partner may count more in a spouse's decision-making if that partner is sick; the length of the planning horizon may change because of a possible death; and the expectations about appropriate behaviour may change.

\subsection{Fertility}

Fertility is one possible mediating factor. Cancer has been found to reduce birth rates with an overall effect of about $25 \%$ both in Norway and other countries, probably because of lower fecundity as well as weaker fertility desires (Syse, Kravdal, and Tretli 2007). The strongest effects have been seen for women with gynaecological cancers and men with testicular cancer, though these effects have diminished over time as a result of in vitro fertilization and cryopreservation of semen (Syse, Kravdal, and Tretli 2007, Fossa and Kravdal 2000). Further, having children increases the partners' benefit from the relationship compared to the alternatives (living alone or with another partner), and many parents may fear that a disruption could harm their child(ren). Accordingly, divorce rates tend to be higher among childless couples, and to a lesser extent among one-child couples, than among those with more children, though such effects also pick up an effect of marital quality on childbearing (Lillard and Waite 1993). 


\subsection{Intimacy and sexuality}

Chronic illnesses in general and certain cancer forms in particular may influence physical intimacy and sexuality, and thereby divorce rates. For example, it has been reported than men with urogential or colorectal cancer may experience erectile and ejaculatory dysfunction related to damage to the autonomic nervous system or a reduced circulation of blood to the penis (Nazareth, Lewin, and King 2001). Hormonal impairment of sexual function is less common, but some men with cancer in the aforementioned organs, as well as cancer in the brain, leukaemia and lymphoma, experience a general decrease in libido (Nazareth, Lewin, and King 2001). Among women, sudden premature ovarian failure and direct effects of radiation fibrosis or surgical scar tissue may cause pain with sexual activity (Bergmark et al. 1999). In addition, altered physical appearance due to e.g. a stoma, limb amputation or removal of a breast may affect sexuality both for men and women, and fatigue and chronic weakness may decrease libido (Schover 2005). Another issue is that a person's gender identity and 'sense of self' may be disturbed because of cancer in reproductive organs, with implications for the sexual desires (Fobair et al. 2006, Nazareth, Lewin, and King 2001). Some have argued that this is particularly true for men (Monga et al. 2004, Joly et al. 2002).

All these effects depend on both the extent of disease and on type of treatment received (Dorval et al. 2005, Joly et al. 2002, Nazareth, Lewin, and King 2001, Bergmark et al. 1999). Many treatment regiments have become less aggressive over the last few decades, both as a result of technological innovations and an increased awareness and recognition of cancer survivors' sexual functioning. For many localized cancers today, treatment may actually be presumed to be physically nearly nonafflicting. For more advanced cancers, however, treatments that harm sexual organs and/or hormonal production are still employed to cure the disease, as alternatives do not exist.

\subsection{Income and education}

It is also possible that cancer affects divorce rates through education, occupation and income. Cancer in adolescent years may, for instance, reduce the chances of getting a higher education, with long-term implications for income. Besides, cancer illness may interfere with work capability and opportunity, and thus reduce income (Bradley and Bednarek 2002, Spelten, Sprangers, and Verbeek 2002). Moreover, high costs of treatment and rehabilitation may affect a family's financial situation, although the impact in Norway may be modest compared to countries with less extensive public 
welfare systems (Blekesaune, Øverbye, and Romøren 2003). A lower income is, in turn, likely to affect the chance of divorce. Especially men's income is thought to be inversely related to the divorce rates. In principle, effects of women's earnings depend on whether it is specialization (Becker 1991) or pooling of resources (Oppenheimer 1994) that is most important for the economic value of the relationship, but in accordance with the latter idea, a recent Norwegian investigation showed relatively low divorce rates among women with high incomes (Lyngstad 2006, Kravdal 2001). When the higher income is taken into account, it is likely that the most highly educated, who may be better able to solve conflicts and be more 'interesting' partners, experience the lowest divorce rates (Lyngstad 2006, White 1990).

\subsection{Family orientation and obligations}

Encountering and 'conquering' cancer illness has been suggested to increase family orientation in both cancer patients and their families (Northouse et al. 2000, Manne 1998). There are two aspects of this. One is that the quality of the marital interactions may be enhanced. The illness is often considered by the couple as a common experience, and may thus result in a strengthening of existing bonds between the spouses, perhaps especially if the relationship was good at the outset (Northouse et al. 1998). Another issue is that people with a serious disease may become more conscious about whatever quality there is in the relationship. Later marital conflicts may tend to be seen as small compared to what they have endured previously (Dorval et al. 2005, Schover 2005).

However, it is also possible that cancer illness may affect the quality of the relationship adversely. Poor health may lead to behavioral and mood changes, and various physical, psychological and social effects of cancer will inevitably interfere with persons' abilities to undertake their usual chores and obligations in marital relationships, either temporarily or permanently (Booth and Johnson 1994, White 1990). The healthy spouse may thus experience a 'role overload'. Moreover, if the healthy partner does not already suffer from a 'role overload', he or she may want to get out of the marriage in fear of entering into that situation later.

\subsection{Other potential mediators}

Spouses typically care about each other, and may take each other's well-being into account to some extent even in a situation when divorce is being considered. In particular, a partner who ideally would like to break out of the marriage may hesitate to 
do so if the other is not only opposing it, but also has developed cancer. Besides, there would probably be a strong normative pressure not to leave a seriously ill partner, even in today's individualistic society. A low divorce rate is perhaps particularly likely to be seen initially, and in the most critical periods, when the partner is very ill or there is great uncertainty about survival. There is also another argument for staying together in case of a very aggressive malignancy: it would make little sense to initiate a divorce if death is expected to take its toll in the near future.

\subsection{Interaction effects}

To summarize, cancer illness may increase divorce rates through lower fertility, reduced sexual activity, smaller emotional rewards from the relationship, a larger practical burden on the spouse who is healthy, and perhaps a lower education and income. On the other hand, it is possible that the bonds between the partners are strengthened when they struggle with cancer, and that their values change in such a way that divorce becomes less likely. In addition, a serious disease may 'save' an unsatisfactory relationship because a break-up would be considered inappropriate in such a situation, or because an expected fatal outcome will make it less of an alternative.

Obviously, the relevance of these mechanisms depends on the cancer site and stage, the type of treatment given, and how much uncertainty there is about the outcome. Some examples have already been given. One might also suspect gender differentials, though our knowledge about this is meagre. For example, some authors have suggested that women with cancer are abandoned more often than the other way around (Glantz et al. 2001), which would accord with ideas about gender differences in the commitment to marriage (White 1990). Others have argued that this is an unsubstantiated myth (Dorval et al. 2005, Joly et al. 2002, Glantz et al. 2001, TaylorBrown et al. 2000, Dorval et al. 1999, Joly et al. 1996), and that ill health in general is perceived by both the male and female partner as lowering the quality of the marriage, irrespective of whether he or she is affected (Booth and Johnson 1994).

The effect of a malignancy probably also depends on whether it occurred before or after marriage. In the former case, the spouses are aware of many (but not necessarily all) consequences of the disease at the time of marriage, and apparently accept them. It is possible, however, that the relationship is poorer than for persons for whom all the other observed variables are the same, so that later strains are more likely to lead to divorce. Cancer would thus be a co-determinant rather than a factor acting alone, as opposed to cancer occurring after marriage. One might therefore expect weaker effects. In addition, the arguments related to short durations since diagnosis and uncertainty 
about the outcome are less likely to be relevant when the cancer is diagnosed before marriage.

Finally, interactions with the spouses' age and duration of marriage at the time of diagnosis are plausible. One reason is that arguments related to fertility are relevant only for the rather young adults. Another reason may be that reduced work opportunities and lower incomes may be seen as particularly problematic in a phase where one is trying to settle-in both occupationally and economically (Schroevers, Ranchor, and Sanderman 2004, Joly et al. 2002, Northouse et al. 1998, Joly et al. 1996, Booth et al. 1986). Among the elderly, gainful work is not an issue. It is also possible that sexual problems or a weakening of the emotional rewards from the union are particularly devastating early in a relationship, and that an increased care load is most difficult to accept at an age when illness is most unexpected (Booth et al. 1986).

\subsection{Potential confounders}

Certain factors may influence both the chance of getting a malignant disease and, for completely different reasons, the divorce rate. These should ideally be controlled for. Most importantly, there has been a change over time in certain behaviours and environmental exposures that are important for the incidence of various cancers, and there have also been socioeconomic, ideational and other changes with implication for the marital stability. We therefore include calendar period in the models. Moreover, it is well known that people's age affect both their chance of getting cancer and their divorce rates. The latter effect partly reflects the link between current age, age at marriage, and duration of marriage, all of which are strong determinants of divorce (e.g. Booth and Edwards 1985). We have included current age and duration of the marriage in the models.

Two factors that are more problematic are fertility and education. As just explained, cancer may operate through these factors in affecting the divorce rate. In addition, both may be among the determinants of certain cancer forms, including those considered here. For example, fertility is widely assumed to affect the chance of developing breast, endometrial, and ovarian cancer, with the risk of cancer declining with increasing parity (Harvard Report on Cancer Prevention 1996). According to the same report, the inverse is true for cervical cancer development. In addition, the report states that a high level of socioeconomic resources will increase the chances of developing breast cancer and melanoma, while reducing the chance of, for example, lung, stomach and cervical cancer. We include parity and educational level in our models, but also refer estimates from models where these variables are left out. 
Unfortunately, these variables cannot capture all potential confounders. Given age, period, education and parity, there are differences in people's life style that probably affect both the risk of getting cancer and the divorce rate. A high number of sexual partners is one example: in addition to destabilizing marriages for obvious reasons, having many partners increases the chance of being infected with the Human Papilloma Virus, which is a very common virus and an etiological factor in the development of cervical cancer (Syrjanen 1994).

\section{Data and method}

\subsection{Data}

The analyses cover the period 1974-2001 and are based on data from three different sources linked together with permission from the National Data Inspectorate by means of the personal identification number assigned to everyone who has lived in Norway after 1960. Information on date of birth, date of death or migration, dates of birth of all children for whom the person is registered as mother or father, and marital status at the beginning of each year from 1974 was extracted from the Norwegian Population Register. Educational level was taken from the population censuses of 1970, 1980, and 1990, and information on cancer was drawn from the Cancer Registry of Norway, which has registered all cancer diagnoses at a national level since 1953. Mandatory reporting from clinicians, pathologists, and death certificates ensures completeness and high data quality on cancer form and stage (Tingulstad et al. 2002, Harvei, Tretli, and Langmark 1996). In line with standard practice, persons with basal cell carcinoma were not included as diagnosed with cancer in the present study, but remained members of the general population. The analyses were restricted to women and men born 1900-83. The cut-off was set to 1983 because younger birth cohorts have not had sufficient time to marry by the end of follow-up, which was December $31^{\text {st }} 2001$.

\subsection{Statistical approach}

Individual women and men were followed from the time of marriage with the intention of exploring how a cancer diagnosis would affect their divorce rate. Only characteristics of the person in focus are included, not those of the spouse. This equals using the couple as a unit and estimating two models: one where a variable indicating cancer of the male partner is included along with other characteristics of the man, and one with corresponding variables for the female partner. Such an approach should be adequate. If 
spouses' chances of having cancer were positively correlated, an effect of the male partner's cancer on the divorce rate would in part reflect that the female partner may have a cancer that influences marital stability, and vice versa. However, such correlations can be discounted (Friedman and Quesenberry 1999, Iversen et al. 1997). Moreover, the procedure only allows us to control for one partner's age, education and fertility, but this should be of little concern. In principle, a person's chance of developing cancer may be affected also by the partner's parity, age and education (though not necessarily through the same factors as one's own parity, age and education operate), and these factors may also contribute to the divorce rate. However, when own parity, age and education turned out to be of little importance as control variables (see below), and they are so strongly correlated with the corresponding characteristics of the partner (Birkelund and Heldal 2003), we do not expect leaving out the latter to influence our results.

Discrete-time hazard regression models (Allison 1995) for divorce were estimated, using the Proc Logistic procedure in $\mathrm{SAS}^{\circledR}$ 9.1. A divorce is assumed to have taken place if the marital status changes from 'married' or 'separated' at the beginning of one year to 'divorced' at the beginning of the following year. Persons who were married in 1974 contributed a series of one-year observations from 1974 to the time of divorce, unless emigration, death, death of spouse, or end of follow-up occurred earlier. Those who were not married in 1974 contributed a similar series of one-year observations from the time of marriage after 1974, if any. Only the first recorded marriage was considered. This may be a second- or higher-order marriage if persons were divorced or widowed in 1974. A logistic model for the probability of divorce within the year was estimated from the entire set of one-year observations for all persons, men and women separately.

Mathematically, the model is

$$
\log (\mathbf{p} /(1-\mathbf{p}))=\alpha_{0}+\alpha_{1} X+\alpha_{2} D
$$

where $\mathrm{p}$ is the divorce probability within the twelve-month interval, D is a vector of cancer disease characteristics, and $\mathrm{X}$ is a vector of other covariates.

\subsection{Detailed model specifications}

Several specifications of the cancer variable D were used. In one model, a distinction was made between no cancer and any cancer to explore overall effects. In other models, distinctions were made between cancers diagnosed less than five years earlier and cancers diagnosed further back in time, or a finer categorization of time since diagnosis 
was employed. Further, it was differentiated between various common cancer forms, 12 for men and 13 for women. The disease variables were lagged one year. This is because a no-fault divorce is granted after a formal separation period of one year. The actual separation may have taken place even earlier. Thus, if there were an association between having a very recent cancer diagnosis at the beginning of a certain year and the chance of divorce during that year, it would not be likely to reflect a casual effect of cancer, which would need more time to be felt. However, we also estimated models without lag, or with a lag of two years, and the results varied very little.

Age, period, duration of marriage, education and parity were included in the $\mathrm{X}$ vector. These variables referred to the situation in the beginning of the year under consideration, except education, which is taken from the last previous census. Because full birth histories are not available for people born before 1935, the parity variable has one category for 'unknown; born before 1935'. Excluding this group did not alter the main results. It was experimented with various categorizations, including a finer categorization of duration of marriage, but the cancer effects were always the same.

The $\mathrm{X}$ vector also included an indicator of whether the marriage was already started in 1974. Because information on marital status only goes back to 1974, we do not know the duration of those marriages. It is arbitrarily set to 1 year, but any number would do (the decision has no impact on the duration effects as long as the married-in1974 indicator is included). One might consider leaving out the marriages with unknown duration, but the control for duration turned out to be unimportant anyway, and models estimated separately for marriages contracted before and after 1974 gave very similar results (not shown). We also included an indicator of whether the marriage was a first marriage (which could not be known if it was initiated before 1974), but this had no impact on the other estimates.

To further explore variations in the cancer effects, we also estimated models that included interactions between disease variables and some of the other variables.

\section{Results}

\subsection{The size of the material}

Our material consisted of a total of 1.42 million married men and 1.44 million married women, each contributing an average of 16.9 observation years. The total number of divorces was 241051 among men and 245258 among women. ${ }^{3}$ Included in the above

\footnotetext{
${ }^{3}$ The number of individuals and divorces are not equal among males and females because some individuals are married to and divorced from either non-residential Norwegians or non-Norwegian persons. These individuals are not included in our analyses.
} 
numbers were 118687 male cancer survivors for whom 1940 divorces were registered, while the respective number among the 97897 female cancer survivors was 2901 .

\subsection{Overall effects}

Married men with a cancer of any form, diagnosed at any time, had a divorce rate that was eight percent lower (odds ratio (OR) 0.92, $95 \%$ confidence interval (CI) 0.88-0.97) than that of men without a cancer diagnosis for whom all the other observed variables were similar. No overall effect of cancer was seen for women (OR 0.98, CI 0.94-1.01). However, both men and women with a relatively recent cancer diagnosis (0-5 years earlier) had lower divorce rates than those without cancer (OR 0.90 CI 0.84-0.95 for men, and OR 0.94 CI 0.89-0.99 for women). Those with a cancer diagnosed further back in time (> 5 years) had no particularly low or high divorce rate (OR 0.95 CI 0.901.02 for men, and OR 1.01 CI 0.96-1.06 for women). Estimates from a model with a finer subdivision of duration are shown in table 1 . The lowest divorce rates were estimated the first two and a half years after diagnosis. After this period, the divorce rates were equal to those of the general population for men, whereas for women an excess divorce rate of eight percent was observed ten to twenty years following diagnosis.

Table 1: Effects of cancer, age, education, period, marriage duration, parity, marriage order, and marital status in 1974 on divorce probability

\begin{tabular}{lllll}
\hline & Men & & Women & \\
& OR $^{\mathrm{a}}$ & $\mathrm{Cl}^{\mathrm{b}}$ & $\mathrm{OR}$ & $\mathrm{Cl}$ \\
\hline Cancer & & & & \\
No cancer & 1.00 & & 1.00 & \\
Cancer 5 2.5 yrs & 0.83 & $0.76-0.90$ & 0.88 & $0.82-0.95$ \\
Cancer 2.6-5.0 yrs & 1.00 & $0.91-1.10$ & 1.02 & $0.94-1.10$ \\
Cancer 5.1-10.0 yrs & 0.92 & $0.84-1.01$ & 0.99 & $0.92-1.07$ \\
Cancer 10.1-20.0 yrs & 1.00 & $0.90-1.10$ & 1.08 & $1.00-1.17$ \\
Cancer > 20.0 yrs & 0.94 & $0.78-1.13$ & 0.86 & $0.73-1.01$ \\
\hline
\end{tabular}


Table 1: (continued)

\begin{tabular}{|c|c|c|c|c|}
\hline & \multicolumn{2}{|l|}{ Men } & \multicolumn{2}{|c|}{ Women } \\
\hline & $\mathrm{OR}^{\mathrm{a}}$ & $\mathrm{Cl}^{\mathrm{b}}$ & OR & $\mathrm{Cl}$ \\
\hline \multicolumn{5}{|l|}{ Attained age (yrs) } \\
\hline Age 17-19 & 1.90 & $1.47-2.46$ & 1.85 & $1.72-1.98$ \\
\hline Age 20-24 & 1.28 & $1.25-1.31$ & 1.34 & $1.31-1.36$ \\
\hline Age $25-29$ & 1.00 & & 1.00 & \\
\hline Age $30-34$ & 0.86 & $0.85-0.88$ & 0.81 & $0.80-0.82$ \\
\hline Age 35-39 & 0.76 & $0.75-0.78$ & 0.69 & $0.68-0.70$ \\
\hline Age $40-44$ & 0.66 & $0.65-0.68$ & 0.55 & $0.54-0.56$ \\
\hline Age $45-49$ & 0.51 & $0.50-0.52$ & 0.38 & $0.37-0.39$ \\
\hline Age $50-54$ & 0.34 & $0.33-0.34$ & 0.22 & $0.21-0.22$ \\
\hline Age 55-59 & 0.20 & $0.19-0.20$ & 0.12 & 0.12 .0 .13 \\
\hline Age $60-64$ & 0.11 & $0.10-0.11$ & 0.06 & $0.06-0.07$ \\
\hline Age $65-69$ & 0.06 & $0.06-0.07$ & 0.04 & $0.04-0.04$ \\
\hline Age $70-74$ & 0.03 & $0.03-0.03$ & 0.02 & $0.02-0.02$ \\
\hline Age $75-79$ & 0.02 & $0.02-0.02$ & 0.01 & $0.01-0.01$ \\
\hline Age $\geq 80$ & 0.01 & $0.01-0.01$ & 0.01 & $0.01-0.01$ \\
\hline \multicolumn{5}{|l|}{ Educational level } \\
\hline$<$ Elementary level $^{d}$ & 1.15 & $1.12-1.18$ & 1.11 & $1.08-1.13$ \\
\hline Elementary level & 1.00 & & 1.00 & \\
\hline High school level & 0.86 & $0.85-0.87$ & 0.83 & $0.82-0.84$ \\
\hline Bachelor level & 0.73 & $0.72-0.74$ & 0.75 & $0.74-0.76$ \\
\hline$\geq$ Master level & 0.69 & $0.68-0.70$ & 0.75 & $0.72-0.77$ \\
\hline \multicolumn{5}{|l|}{ Calendar period } \\
\hline 1974-1979 & 0.88 & $0.86-0.89$ & 0.86 & $0.85-0.88$ \\
\hline 1980-1984 & 1.00 & & & \\
\hline 1985-1989 & 1.16 & $1.14-1.17$ & 1.21 & $1.19-1.23$ \\
\hline 1990-2001 & 1.53 & $1.51-1.55$ & 1.63 & $1.61-1.65$ \\
\hline
\end{tabular}


Table 1: (continued)

\begin{tabular}{|c|c|c|c|c|}
\hline & Men & & Wom & \\
\hline & $\mathrm{OR}^{\mathrm{a}}$ & $\mathrm{Cl}^{\mathrm{b}}$ & OR & $\mathrm{Cl}$ \\
\hline \multicolumn{5}{|c|}{ Duration of marriage (yrs) } \\
\hline$<1.0$ & 0.68 & $0.66-0.69$ & 0.69 & $0.67-0.70$ \\
\hline $1.0-1.9$ & 1.00 & & 1.00 & \\
\hline $2.0-3.9$ & 1.07 & $1.06-1.09$ & 1.11 & $1.09-1.13$ \\
\hline $4.0-5.9$ & 1.10 & $1.08-1.12$ & 1.16 & $1.14-1.18$ \\
\hline$\geq 6.0$ & 1.03 & $1.01-1.05$ & 1.11 & $1.09-1.14$ \\
\hline \multicolumn{5}{|c|}{ Number of children (parity) } \\
\hline unknown (born < 1935) & 0.74 & $0.72-0.75$ & 0.73 & $0.71-0.74$ \\
\hline 0 & 1.33 & $1.31-1.35$ & 1.27 & $1.25-1.29$ \\
\hline 1 & 1.00 & & 1.00 & \\
\hline 2 & 0.75 & $0.74-0.75$ & 0.76 & $0.75-0.77$ \\
\hline 3 & 0.65 & $0.64-0.66$ & 0.66 & $0.66-0.67$ \\
\hline$\geq 4$ & 0.67 & $0.66-0.68$ & 0.68 & $0.66-0.69$ \\
\hline \multicolumn{5}{|l|}{ Marital status in 1974} \\
\hline Not married & 1.00 & & 1.00 & \\
\hline Married & 0.94 & $0.93-0.95$ & 0.99 & $0.98-1.00$ \\
\hline \multicolumn{5}{|l|}{ First or second marriage } \\
\hline First & 1.00 & & 1.00 & \\
\hline Second & 3.11 & $3.03-3.18$ & 2.86 & $2.80-2.93$ \\
\hline
\end{tabular}

${ }^{a}$ Odds ratio. ${ }^{b} 95 \%$ confidence interval. ${ }^{c}$ The cancer estimates were almost identical when only persons below 75 years of age were included. ${ }^{d}$ Including persons with unknown educational status

\subsection{Site-specific effects}

The effects vary across cancer sites. For example, men with non-Hodgkin's disease, leukaemia, colorectal, prostate, and lung cancer show relatively low divorce rates. The point estimates suggest a reduction of about 20-35\% (table 2). These 'protective effects' were only significant during the first few years after diagnosis. On the other hand, a relatively recent diagnosis of testicular cancer increased the divorce probability 
for men by around $20 \%$. This is the only cancer form among men that led to a significantly increased divorce rate.

Also colorectal cancer in women was associated with a reduction in the divorce probability during the first years after diagnosis (table 3), but not the other gendernonspecific cancers for which such effects were seen among men. However, women with skin or head and neck cancer had a relatively low divorce rate during the first years, as had women with typical female cancer forms: breast, ovarian or uterine cancer. After five years, no significant reductions in divorce rates were observed. On the other hand, cervical cancer was associated with a significantly increased divorce rate of about $40 \%$. The effect was strongest the first few years after diagnosis, but still significant at longer durations since diagnosis ( $55 \%$ vs. $25 \%)$.

The point estimates suggested a relatively high divorce rate for men and women with brain cancer, but significance was not attained.

Table 2: Various cancer forms' effect on the divorce probability among men ${ }^{\mathrm{a}}$

\begin{tabular}{|c|c|c|c|c|c|c|c|}
\hline \multirow[b]{2}{*}{ Cancer form } & \multirow[b]{2}{*}{$\mathrm{N} /$ pyrs $^{\mathrm{b}}$} & \multicolumn{2}{|c|}{ Overall } & \multicolumn{2}{|c|}{$0-5 \mathrm{yrs}$} & \multicolumn{2}{|c|}{$>5 \mathrm{yrs}$} \\
\hline & & $\mathrm{OR}^{\mathrm{c}}$ & $\mathrm{Cl}^{\mathrm{d}}$ & OR & $\mathrm{Cl}$ & OR & $\mathrm{Cl}$ \\
\hline No cancer & 239111/23.3 mill & 1.00 & & & & & \\
\hline Testicular cancer & $455 / 40321$ & 1.05 & $0.96-1.16$ & 1.19 & $1.04-1.38$ & 0.97 & $0.86-1.10$ \\
\hline Skin cancer & $351 / 90196$ & 0.96 & $0.86-1.06$ & 0.92 & $0.80-1.08$ & 0.99 & $0.86-1.15$ \\
\hline Renal/Bladder cancer & $179 / 94137$ & 0.88 & $0.76-1.02$ & 0.93 & $0.77-1.12$ & 0.80 & $0.64-1.02$ \\
\hline Colorectal cancer & $154 / 97944$ & 0.80 & $0.68-0.93$ & 0.74 & $0.61-0.91$ & 0.88 & $0.69-1.13$ \\
\hline Head/Neck cancer & $115 / 45850$ & 1.00 & $0.83-1.20$ & 0.98 & $0.76-1.28$ & 1.02 & $0.78-1.32$ \\
\hline Hodgkin & $113 / 9546$ & 1.02 & $0.85-1.23$ & 1.10 & $0.80-1.51$ & 0.99 & $0.78-1.24$ \\
\hline Prostate cancer & $106 / 155580$ & 0.81 & $0.67-0.98$ & 0.80 & $0.65-1.00$ & 0.85 & $0.57-1.27$ \\
\hline Brain cancer & $101 / 8488$ & 1.12 & $0.92-1.37$ & 1.19 & $0.89-1.58$ & 1.07 & $0.81-1.40$ \\
\hline Non-Hodgkin & $91 / 21408$ & 0.80 & $0.65-0.99$ & 0.74 & $0.54-1.00$ & 0.86 & $0.65-1.14$ \\
\hline Endocrine cancer & $62 / 9315$ & 1.01 & $0.79-1.30$ & 0.96 & $0.63-1.46$ & 1.04 & $0.76-1.42$ \\
\hline Leukaemia & $47 / 20561$ & 0.67 & $0.50-0.89$ & 0.65 & $0.45-0.93$ & 0.70 & $0.44-1.12$ \\
\hline Lung cancer & $45 / 28247$ & 0.66 & $0.49-0.88$ & 0.57 & $0.40-0.83$ & 0.87 & $0.54-1.40$ \\
\hline Other cancer & $121 / 44670$ & 0.83 & $0.70-0.99$ & 0.62 & $0.46-0.83$ & 1.06 & $0.84-1.33$ \\
\hline
\end{tabular}

${ }^{a}$ Only the effects of the disease variable are displayed in this table, but all the variables shown in table 1 were included in the model.

${ }^{b}$ Number of divorces among persons in this category/person-years of observation. ${ }^{c}$ Odds ratio. ${ }^{d} 95 \%$ confidence interval 
Syse \& Kravdal: Does cancer affect the divorce rate?

Table 3: $\quad$ Various cancer forms' effect on the divorce probability among women $^{\mathrm{a}}$

\begin{tabular}{|c|c|c|c|c|c|c|c|}
\hline & & Overe & & $0-5$ yrs & & $>5 \mathrm{yr}$ & \\
\hline Cancer form & $\mathrm{N} /$ pyrs $^{\text {b }}$ & $\mathrm{OR}^{\mathrm{c}}$ & $\mathrm{Cl}^{\mathrm{d}}$ & OR & $\mathrm{Cl}$ & OR & $\mathrm{Cl}$ \\
\hline No cancer & $242357 / 23.5$ mill & 1.00 & & & & & \\
\hline Cervical cancer & $631 / 90931$ & 1.36 & $1.26-1.47$ & 1.54 & $1.36-1.73$ & 1.25 & $1.12-1.39$ \\
\hline Other gyn. cancer & $381 / 125011$ & 0.86 & $0.78-0.96$ & 0.78 & $0.67-0.91$ & 0.94 & $0.82-1.07$ \\
\hline Breast cancer & $715 / 242228$ & 0.92 & $0.85-0.99$ & 0.90 & $0.81-0.99$ & 0.95 & $0.85-1.06$ \\
\hline Skin cancer & $407 / 82586$ & 0.89 & $0.80-0.98$ & 0.87 & $0.75-1.01$ & 0.90 & $0.79-1.03$ \\
\hline Endocrine cancer & $206 / 30533$ & 0.98 & $0.85-1.12$ & 0.99 & $0.79-1.24$ & 0.97 & $0.82-1.16$ \\
\hline Colorectal cancer & $121 / 73447$ & 0.83 & $0.69-0.99$ & 0.78 & $0.62-0.99$ & 0.90 & $0.68-1.18$ \\
\hline Hodgkin & $83 / 6733$ & 1.13 & $0.91-1.40$ & 0.89 & $0.57-1.39$ & 1.23 & $0.96-1.58$ \\
\hline Brain cancer & $77 / 6754$ & 1.15 & $0.92-1.44$ & 1.09 & $0.77-1.56$ & 1.19 & $0.89-1.59$ \\
\hline Renal/Bladder cancer & $61 / 24893$ & 1.03 & $0.80-1.32$ & 1.09 & $0.78-1.53$ & 0.96 & $0.66-1.41$ \\
\hline Non-Hodgkin & $56 / 15636$ & 0.80 & $0.62-1.04$ & 0.84 & $0.59-1.20$ & 0.76 & $0.51-1.12$ \\
\hline Leukaemia & $34 / 12033$ & 0.83 & $0.59-1.17$ & 0.61 & $0.36-1.03$ & 1.12 & $0.72-1.74$ \\
\hline Head/Neck cancer & $26 / 10203$ & 0.78 & $0.53-1.15$ & 0.50 & $0.25-0.99$ & 1.05 & $0.66-1.68$ \\
\hline Lung cancer & $23 / 8146$ & 0.82 & $0.54-1.24$ & 0.70 & $0.41-1.21$ & 1.05 & $0.56-1.96$ \\
\hline Other cancer & $80 / 24993$ & 0.82 & $0.65-1.02$ & 0.64 & $0.44-0.93$ & 0.96 & $0.73-1.26$ \\
\hline
\end{tabular}

${ }^{a}$ Only the effects of the disease variable are displayed in this table, but all the variables shown in table 1 were included in the model. ${ }^{b}$ Number of divorces among persons in this category/person-years of observation. ${ }^{c}$ Odds ratio. ${ }^{d} 95 \%$ confidence interval

\subsection{The importance of cancer stage and prognosis}

Cancer that has spread to distant organs at the time of diagnosis (metastatic cancer) reduces the divorce rate most markedly, while there is no difference in the divorce rate between men and women with localized cancer and those without cancer (table 4). This probably reflects the particularly poor prognosis of the metastatic cancers.

Similarly, when we group the cancer sites into two categories, depending on whether the expected five-year survival is below or above $75 \%$ according to published statistics, we find that the divorce rate is most markedly reduced for those having one of the cancers with the poorest prognosis. For men, the OR associated with the least fatal 
cancers was 0.95 (CI 0.90-0.99), as opposed to an OR of 0.86 (CI 0.77-0.95) for the most fatal ones. The corresponding figures for women were 1.07 (CI 1.01-1.13) and 0.91 (CI 0.86-0.95).

Table 4: Divorce probability by cancer stage ${ }^{a}$

\begin{tabular}{lllll}
\hline & Men & & Women & \\
& OR $^{\mathrm{b}}$ & $\mathbf{C l}^{\mathrm{c}}$ & OR & $\mathbf{C l}$ \\
\hline No cancer & 1.00 & & 1.00 & \\
Local cancer & 0.97 & $0.91-1.02$ & 1.00 & $0.96-1.05$ \\
Regional cancer & 0.87 & $0.78-0.97$ & 0.89 & $0.81-0.98$ \\
Metastatic cancer & 0.53 & $0.35-0.81$ & 0.61 & $0.41-0.91$ \\
Cancer, stage unknown $^{\mathrm{d}}$ & 0.85 & $0.75-0.97$ & 0.95 & $0.82-1.10$ \\
\hline
\end{tabular}

${ }^{a}$ Only the effect of cancer stage is displayed in this table, but all the variables shown in table 1 were included in the model.

${ }^{b}$ Odds ratio. ${ }^{c} 95 \%$ confidence interval. ${ }^{\text {I Including lymphomas, leukaemia, and missing }(<10 \%)}$

\subsection{Cancer before or after marriage}

Since cancer is a disease that increases sharply with increasing age, survivors of childhood cancers (below 18 years at diagnosis) account for about $2.5 \%$ of the total cancer person-years. The great majority of persons with cancer included in this study got their diagnosis while they were married (> $75 \%)$. The divorce-reducing effect of cancer, when all sites are pooled, is restricted to the latter group (OR 0.89 (CI 0.850.94) for men and OR 0.94 (CI 0.90-0.98) for women). The OR for childhood and young adult survivors was 1.03 (CI 0.93-1.15) for men and 1.03 (CI 0.92-1.14) for women. For those for whom the order of marriage and cancer could not be established due to the previously described unknown durations of some marriages, the OR was 0.97 (0.86-1.10) for men and 1.14 (1.05-1.25) for women.

\subsection{Age interactions}

An interaction term between various cancer forms and age as a continuous variable revealed that among women, cervical cancer had a significantly more deleterious effect on divorce rates at younger ages (OR at 20 years: 1.69) compared to older (OR at 60 
years: 1.19). Similar results were seen upon stratification on age below and above fifty years, with ORs being 1.42 (CI 1.30-1.56) and 1.24 (CI 1.06-1.44), respectively. This was the only cancer form among women for whom an age effect was observed. Among men, significant declines in the effects of cancer with increasing age were seen for renal and bladder cancer, leukaemia, and testicular cancer. ORs at 20 years were estimated to be $1.50,1.23$, and 1.34, respectively. Corresponding ORs at 60 years were 0.82, 0.50, and 0.84 . Once again, a similar pattern was seen when a distinction was made between ages below and above 50 years.

\subsection{Fertility and education as mediating factors?}

Fertility and education were included in the models because they are potential confounders. However, they may also be causally intermediate factors. In this study, the estimates did not change when these two factors were left out (not shown).

\section{Discussion and conclusion}

There are several reasons why a malignant disease might be expected to affect the divorce rates, in either direction, but except for the testicular and cervical cancers, it seems that the divorce-reducing effects dominate or at least balance the opposite contributions, or that both types of effects are weak. With regards to mechanisms, all we can conclude from this study is that at least the potentially harmful effects through fertility and lower educational achievements are unimportant. Cancer among women is not generally more harmful to a marriage than cancer among men, as suggested by some investigators, but there are certain gender differences: whereas colorectal cancer in both men and women reduces divorce rates, other malignancies have an effect only if they occur in men, or only if they occur in women. This pattern is hard to explain.

The divorce rate is most clearly reduced the first few years after diagnosis, for cancers that have already spread to other organs at the time of diagnosis, and for cancer forms that tend to have poor prognosis. This lends support to the idea that people may consider it both unfair and unsatisfactory to end a substandard relationship when a spouse is in such a critical situation. It may, as well, be possible that partners experience a particular strengthening of their relationship under such circumstances.

These arguments are relevant also for testicular and cervical cancers, though probably less so, as these cancers are among the least aggressive. However, there are apparently other mechanisms pushing in the opposite direction. Above all, these cancer forms may lead to changes in intimacy and sexuality (Schover 2005, Nazareth, Lewin, 
and King 2001, Bergmark et al. 1999), depending on the kind of treatment that is given and the detailed characteristics of the disease. They are likely to affect fertility, though the latter appears to matter little in this population. Another relevant issue is that cervical and testicular cancers are the cancer forms with the lowest mean age at diagnosis. It is seen for several cancer sites that the effects of cancer are most adverse or least beneficial at the youngest ages, when people typically also have been married for the shortest period. Finally, it is possible that the observed effects are partly or fully spurious. For example, the high divorce rate among women with cervical cancer may reflect a high number of sexual partners of either spouse. It is more difficult to suggest factors that can be determinants of both testicular cancer and divorce (Harvard Report on Cancer Prevention 1996).

Brain cancer may be extremely debilitating and alter both physical and psychological functioning dramatically, thereby interfering strongly with the ability to fill spousal roles. Unless this is counterbalanced by the particularly poor prognosis of this cancer form, one would expect to see a relatively high divorce rate. The point estimates do indeed point in this direction both for men and women, and thus support some earlier findings based on rather small samples, but significance is not attained.

Norway is a liberal country with general divorce rates equal to that of other developed countries, and our findings, therefore, may be hypothesized to pertain also to these countries. On the other hand, our findings may be restricted to societies where public health care systems are in place to ensure good cancer care for all, and where extensive welfare systems facilitate adequate economic compensations for drops in household income. This remains to be explored.

To summarize, one might expect a stressor such as a malignant disease to reduce the quality of a marital relationship in many ways, but other factors apparently tend to counterbalance such effects. However, cervical cancer and testicular cancer are exceptions. Persons experiencing these diseases, and their spouses, thus suffer from a double punishment: in addition to all the worries and pains they have to go through, they run a higher chance of seeing their marriage broken. Given this situation, additional resources for marriage counselling should perhaps be made available. In addition, practical support to aid with childcare or housework could be provided, and rights to a less demanding work situation to reduce 'role overload' on the healthy spouse as well as 'unburden' the person with cancer could be established. 


\section{Acknowledgements}

This research was supported by a grant from the Norwegian Foundation of Health and Rehabilitation. Øystein Kravdal worked at the Centre for Advanced Study at the Norwegian Academy of Science and Letters when the last parts of the analyses were done. 


\section{References}

Allison, P. D. 1995. Survival Analysis Using SAS ${ }^{\circledR}$ : A Practical Guide. Cary, NC: SAS Institute Inc.

Becker, G. S. 1991. A Treatise on the Family. Cambridge, MA: Harvard University Press.

Becker, G. S., Landes, E. M., and Michael, R. T. 1977. "An Economic Analysis of Marital Instability." Journal of Political Economy 85(6):1141-87.

Bergmark, K., Lundqvist, E., Dickman, P. W., Henningsohn, L., and Steineck, G. 1999. "Vaginal Changes and Sexuality in Women With a History of Cervical Cancer." N.Engl.J Med. 340(18):1383-89.

Birkelund, G. E. and Heldal, J. 2003. "Who Marries Whom? Educational Homogamy in Norway." Demographic Research 8(1):1-30.

Blekesaune, M., Øverbye, E., and Romøren, T. I., Blekesaune, M., Øverbye, E., and Romøren, T. I. 2003. Health selection in marital transitions: Evidence from administrative data. 22/03. Oslo: NOVA.

Booth, A. and Edwards, J. N. 1985. "Age at Marriage and Marital Instability." Journal of Marriage and the Family 47(1):67-75.

Booth, A. and Johnson, D. R. 1994. "Declining Health and Marital Quality." Journal of Marriage and the Family 56(2):218-23.

Booth, A., Johnson, D. R., White, L. K., and Edwards, J. N. 1986. "Divorce and Marital Instability Over the Life Course." J.Fam.Issues 7(4):421-42.

Bradley, C. J. and Bednarek, H. L. 2002. "Employment Patterns of Long-Term Cancer Survivors." Psycho-Oncology 11(3):188-98.

Byrne, J., Fears, T. R., Steinhorn, S. C., Mulvihill, J. J., Connelly, R. R., Austin, D. F., Holmes, G. F., Holmes, F. F., Latourette, H. B., and Teta, M. J. 1989. "Marriage and Divorce After Childhood and Adolescent Cancer." JAMA 262(19):2693-99.

Colditz, G., DeJong, W., Hunter, D., Trichopoulos, D., and Willett, W. 1996. "Harvard Report on Cancer Prevention. Volume 1: Causes of Human Cancer." Cancer Causes and Control 7 Suppl 1S3-59.

Dorval, M., Guay, S., Mondor, M., Masse, B., Falardeau, M., Robidoux, A., Deschenes, L., and Maunsell, E. 2005. "Couples Who Get Closer After Breast Cancer: 
Frequency and Predictors in a Prospective Investigation." $J$ Clin.Oncol. 23(15):3588-96.

Dorval, M., Maunsell, E., Taylor-Brown, J., and Kilpatrick, M. 1999. "Marital Stability After Breast Cancer." J Natl.Cancer Inst. 91(1):54-59.

Fobair, P., Stewart, S. L., Chang, S., D'Onofrio, C., Banks, P. J., and Bloom, J. R. 2006. "Body Image and Sexual Problems in Young Women With Breast Cancer." Psycho-Oncology 15(7):579-94.

Fossa, S. D. and Kravdal, O. 2000. "Fertility in Norwegian Testicular Cancer Patients." British Journal of Cancer 82(3):737-41.

Friedman, G. D. and Quesenberry, C. P., Jr. 1999. "Spousal Concordance for Cancer Incidence: A Cohort Study." Cancer 86(11):2413-19.

Glantz, M. J, Cole, B. F., Mills, L., Cross, N., Edwards, K., Recht, L., Cobb, J., and Chamberlain, M. 2001. "High Incidence of Marital Disruption in Women but Not Men With Primary Brain Tumors ." Proc Am Soc Clin Oncol 20(227).

Goldberg, R. J. and Cullen, L. O. 1985. "Factors Important to Psychosocial Adjustment to Cancer: a Review of the Evidence." Soc.Sci.Med. 20(8):803-7.

Harvei, S., Tretli, S., and Langmark, F. 1996. "Quality of Prostate Cancer Data in the Cancer Registry of Norway." Eur.J Cancer 32A(1):104-10.

Iversen, T., Tretli, S., Johansen, A., and Holte, T. 1997. "Squamous Cell Carcinoma of the Penis and of the Cervix, Vulva and Vagina in Spouses: Is There Any Relationship? An Epidemiological Study From Norway, 1960-92." British Journal of Cancer 76(5):658-60.

Joly, F., Henry-Amar, M., Arveux, P., Reman, O., Tanguy, A., Peny, A. M., Lebailly, P., Mace-Lesec'h, J., Vie, B., Genot, J. Y., Busson, A., Troussard, X., and Leporrier, M. 1996. "Late Psychosocial Sequelae in Hodgkin's Disease Survivors: a French Population-Based Case-Control Study." J Clin.Oncol. 14(9):2444-53.

Joly, F., Heron, J. F., Kalusinski, L., Bottet, P., Brune, D., Allouache, N., MaceLesec'h, J., Couette, J. E., Peny, J., and Henry-Amar, M. 2002. "Quality of Life in Long-Term Survivors of Testicular Cancer: a Population-Based Case-Control Study." J Clin.Oncol. 20(1):73-80.

Joung, I. M., van de Mheen, H. D., Stronks, K., van Poppel, F. W., and Mackenbach, J. P. 1998. "A Longitudinal Study of Health Selection in Marital Transitions." Soc.Sci.Med. 46(3):425-35. 
Kravdal, O. 2001. "The Impact of Marital Status on Cancer Survival." Soc.Sci.Med. 52(3):357-68.

Lillard, L. A. and Panis, C. W. 1996. "Marital Status and Mortality: the Role of Health." Demography 33(3):313-27.

Lillard, L. A. and Waite, L. J. 1993. "A Joint Model of Marital Childbearing and Marital Disruption." Demography 30(4):653-81.

Lyngstad, T. H. 2006. "The Impact of Parents' and Spouses' Education on Divorce Rates in Norway." Demographic Research 10(5):121-42.

Manne, S. 1998. "Cancer in the Marital Context: a Review of the Literature." Cancer Invest 16(3):188-202.

Monga, M., Alexandrescu, B., Katz, S. E., Stein, M., and Ganiats, T. 2004. "Impact of Infertility on Quality of Life, Marital Adjustment, and Sexual Function." Urology 63(1):126-30.

Nazareth, I., Lewin, J., and King, M. 2001. "Sexual Dysfunction After Treatment for Testicular Cancer: a Systematic Review." J Psychosom.Res. 51(6):735-43.

Northouse, L. L., Mood, D., Templin, T., Mellon, S., and George, T. 2000. "Couples' Patterns of Adjustment to Colon Cancer." Soc.Sci.Med. 50(2):271-84.

Northouse, L. L., Templin, T., Mood, D., and Oberst, M. 1998. "Couples' Adjustment to Breast Cancer and Benign Breast Disease: a Longitudinal Analysis." PsychoOncology 7(1):37-48.

Oppenheimer, V. K. 1994. "Women's Rising Employment and the Future of the Family in Industrial Societies." Population and Development Review 20(2):293-342.

Rieker, P. P., Fitzgerald, E. M., Kalish, L. A., Richie, J. P., Lederman, G. S., Edbril, S. D., and Garnick, M. B. 1989. "Psychosocial Factors, Curative Therapies, and Behavioral Outcomes. A Comparison of Testis Cancer Survivors and a Control Group of Healthy Men." Cancer 64(11):2399-407.

Schover, L. R. 2005. "Motivation for Parenthood After Cancer: a Review." $J$ Natl.Cancer Inst.Monogr(34):2-5.

Schroevers, M. J., Ranchor, A. V., and Sanderman, R. 2004. "The Role of Age at the Onset of Cancer in Relation to Survivors' Long-Term Adjustment: a Controlled Comparison Over an Eight-Year Period." Psycho-Oncology 13(10):740-752. 
Spelten, E. R., Sprangers, M. A., and Verbeek, J. H. 2002. "Factors Reported to Influence the Return to Work of Cancer Survivors: a Literature Review." Psycho-Oncology 11(2):124-31.

Syrjanen, K. J. 1994. "Human Papillomavirus in Genital Carcinogenesis." Sex Transm.Dis. 21(2 Suppl):S86-S89.

Syse, A., Kravdal, O., and Tretli, S. 2007. "Parenthood After Cancer - A PopulationBased Study." Psycho-Oncology. Available: E-pub ahead of print.

Taylor-Brown, J., Kilpatrick, M., Maunsell, E., and Dorval, M. 2000. "Partner Abandonment of Women With Breast Cancer. Myth or Reality?" Cancer Pract. 8(4):160-164.

Tingulstad, S., Halvorsen, T., Norstein, J., Hagen, B., and Skjeldestad, F. E. 2002. "Completeness and Accuracy of Registration of Ovarian Cancer in the Cancer Registry of Norway." Int.J Cancer 98(6):907-11.

Waldron, I., Hughes, M. E., and Brooks, T. L. 1996. "Marriage Protection and Marriage Selection--Prospective Evidence for Reciprocal Effects of Marital Status and Health." Soc.Sci.Med. 43(1):113-23.

White, L. K. 1990. "Determinants of Divorce: A Review of Research in the Eighties." Journal of Marriage and the Family 52(11):904-12. 